\title{
Bronchopleural Fistula after High-flow Nasal Cannula Use in Patient with COVID-19
}

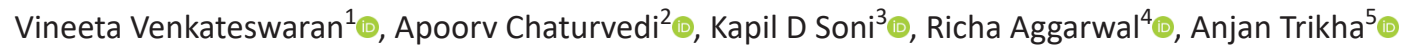

Indian Journal of Critical Care Medicine (2021): 10.5005/jp-journals-10071-23890

Dear Sir,

Severe acute respiratory syndrome coronavirus 2 (SARS-CoV-2), the etiological agent responsible for coronavirus disease2019 (COVID-19) illness, is thought to affect the lung tissue in unique ways. Progressive inflammation of the tracheobronchial tree along with vascular injury can cause severe alveolar destruction. ${ }^{1}$ In addition, these patients frequently have raised mean airway pressures due to the use of novel oxygen delivery devices like high-flow nasal cannula (HFNC). ${ }^{2}$ These factors can be responsible for the increased frequency of pulmonary barotrauma being seen in COVID-19 patients. ${ }^{3}$ While spontaneous pneumothorax, pneumomediastinum, and subcutaneous emphysema are well documented as manifestations of barotrauma in COVID- $19,^{3}$ the occurrence of a bronchopleural fistula (BPF) is extremely rare. ${ }^{4}$ We present the case of a young woman who developed BPF after the use of HFNC in COVID-19.

A 34-year-old woman with COVID-19 acute respiratory distress syndrome (ARDS) and with no known comorbidities was admitted to our institution. She was managed with broad-spectrum antibiotics, steroids, anticoagulants, zinc, and vitamin C. Due to respiratory distress and desaturation, she was administered oxygen via $\mathrm{HFNC}$ at $60 \mathrm{~L}$ /minute with $\mathrm{FiO}_{2}$ titrated to oxygenation and clinical status. She was encouraged to lie in prone and lateral positions. We kept her on oxygen via HFNC for the next 9 days, during which her status gradually improved. Symptoms also improved, except for a persistent dry cough unresponsive to medication. By day 10 of intensive care unit (ICU) stay, her oxygen requirement reduced and she was stable on oxygen via nasal prongs at $4 \mathrm{~L}$ /minute. On day 12 of the ICU stay, the patient complained of dyspnea and chest pain, which was accompanied by an increase in oxygen requirement. An urgent chest radiograph was performed, which revealed a large pneumothorax on the left side. A 32 Fr intercostal drain was inserted, but the repeated chest radiograph showed no improvement in the pneumothorax. Further, bubbling from the intercostal drain was noted. The intercostal drain was repositioned but the pneumothorax persisted. Bronchoscopy was avoided due to the undue high risk of aerosol generation. Computed tomography scan of the chest indicated a diagnosis of BPF (Fig. 1). Negative suction of $10 \mathrm{~cm} \mathrm{H} \mathrm{H}_{2} \mathrm{O}$ applied to the intercostal drain did not improve the lung condition. We considered various options, including thoracoscopy, pleurodesis, and fibrin glue injection to block the fistulous opening. However, the patient deteriorated radiologically as 1,2,5 Department of Anaesthesiology, Pain Medicine and Critical Care,
All India Institute of Medical Sciences, New Delhi, India
3,4Department of Critical and Intensive Care, JPN Apex Trauma Centre,
All India Institute of Medical Sciences, New Delhi, India

Corresponding Author: Kapil D Soni, Department of Critical and Intensive Care, JPN Apex Trauma Centre, All India Institute of Medical Sciences, New Delhi, India, Phone: +91 9718661658, e-mail: kdsoni111@gmail.com

How to cite this article: Venkateswaran V, Chaturvedi A, Soni KD, Aggarwal R, Trikha A. Bronchopleural Fistula after High-flow Nasal Cannula Use in Patient with COVID-19. Indian J Crit Care Med 2021;25(7):830-831.

Source of support: Nil

Conflict of interest: None

well as clinically, with high oxygen requirement, making any procedures difficult. The sharp deterioration necessitated urgent drainage of the pneumothorax. Considering the risk of worsening the lung injury by repeated repositioning of the existing intercostal drain, we instead inserted a fresh intercostal drain of $28 \mathrm{Fr}$; however, this too did not improve the lung condition. Six days after the development of pneumothorax, the patient was intubated due to worsening respiratory failure. She finally succumbed to her illness after 21 days of ICU stay.

SARS-CoV-2 is known to cause inflammation and ulceration of the tracheobronchial tree alongside alveolar wall injury and microthrombi in the pulmonary vasculature. ${ }^{1}$ These histopathological changes lead to a frail and injury-prone lung in COVID-19 patients. $^{3}$ Further, these patients are often on extended periods of oxygen therapy, which in itself can cause trauma to the lung tissue by raising the mean airway pressure. ${ }^{2}$ A BPF results when the tracheobronchial air space ruptures into the pleural space in a diseased lung with impaired wound healing. ${ }^{5}$ We believe that BPF in COVID-19 illness can be multifactorial and even noninvasive modes of ventilation, when used in persistently coughing patients with fragile lungs, may not be completely safe. This case highlights how HFNC oxygen therapy for an extended period in the setting of lung tissue inflammation and destruction can set the stage for a BPF, probably precipitated later by repeated coughing. We found only one case in the literature of BPF in COVID-19,

( ) Jaypee Brothers Medical Publishers. 2021 Open Access This article is distributed under the terms of the Creative Commons Attribution 4.0 International License (https://creativecommons.org/licenses/by-nc/4.0/), which permits unrestricted use, distribution, and non-commercial reproduction in any medium, provided you give appropriate credit to the original author(s) and the source, provide a link to the Creative Commons license, and indicate if changes were made. The Creative Commons Public Domain Dedication waiver (http://creativecommons.org/publicdomain/zero/1.0/) applies to the data made available in this article, unless otherwise stated. 


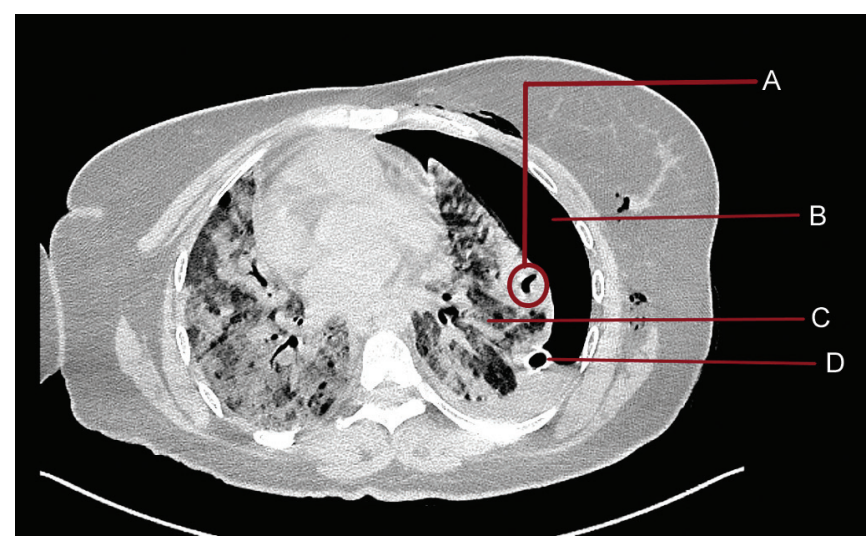

Fig. 1: A: Fistulous opening of bronchopleural fistula; B: Pneumothorax persisting alongside intercostal drain; C: Collapsed underlying lung; D: Intercostal drain

with the patient following a similar clinical course as this case and expiring after 21 days of hospital stay. ${ }^{4}$ We urge our fellow clinicians to anticipate this rare yet devastating complication in patients with COVID-19 pneumonia, especially those on HFNC oxygen therapy for extended periods.

\section{OrCID}

Vineeta Venkateswaran (1) https://orcid.org/0000-0003-2234-8035 Apoorv Chaturvedi $\odot$ https://orcid.org/0000-0002-0683-9101 Kapil D Soni 이 https://orcid.org/0000-0003-1214-4119 Richa Aggarwal (1) https://orcid.org/0000-0002-4531-2759

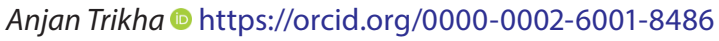

\section{References}

1. Borczuk AC, Salvatore SP, Seshan SV, Patel SS, Bussel JB, Mostyka M, et al. COVID-19 pulmonary pathology: a multi-institutional autopsy cohort from Italy and New York City. Mod Pathol 2020;33(11): 2156-2168. DOI: 10.1038/s41379-020-00661-1.

2. Chauhan Z, Deonarine U, Esteves AR, Asif H, Hernandez F, Ferrer G. Recognizing barotrauma as an unexpected complication of high flow nasal cannula. Chest 2019;156(4):1875A-1876A. DOI: 10.1016/j. chest.2019.08.1619.

3. Lemmers DHL, Hilal MA, Bnà C, Prezioso C, Cavallo E, Nencini N, et al. Pneumomediastinum and subcutaneous emphysema in COVID19: barotrauma or lung frailty? ERJ Open Res 2020;6(4):003852020. DOI: 10.1183/23120541.00385-2020.

4. PlacikDA, Taylor WL, WnukNM. Bronchopleural fistula development in the setting of novel therapies for acute respiratory distress syndrome in SARS-CoV-2 pneumonia. Radiol Case Rep 2020;15(11):2378-2381. DOI: 10.1016/j.radcr.2020.09.026.

5. Salik I, Vashisht R, Abramowicz AE. Bronchopleural fistula. In: StatPearls [Internet]. Treasure Island (FL): StatPearls Publishing; 2020. 